\title{
Hybrid procedure with pulsatile ventricular assist device for hypoplastic left heart syndrome awaiting transplantation
}

Joseph Philip, MD, Karl Reyes, MD, Mohammed Ebraheem, MD, Dipankar Gupta, MD, James C. Fudge, MD, and Mark S. Bleiweis, MD, Gainesville, Fla

From the Congenital Heart Center, UFHealth Shands Children's Hospital, University of Florida, Gainesville, Fla. Disclosures: Authors have nothing to disclose with regard to commercial support.

Received for publication Sept 20, 2018; revisions received Nov 27, 2018; accepted for publication Dec 10, 2018; available ahead of print Feb 6, 2019.

Address for reprints: Mark S. Bleiweis, MD, Congenital Heart Center, University of Florida, 1600 SW Archer Rd, PO Box 100297 UFHSC, Gainesville, FL 32610 (E-mail: bleiweis@ufl.edu).

J Thorac Cardiovasc Surg 2019;158:e59-61

$0022-5223 / \$ 36.00$

Copyright (C) 2018 Published by Elsevier Inc. on behalf of The American Association for Thoracic Surgery https://doi.org/10.1016/j.jtcvs.2018.12.025

$\square$ Video clip is available online.

In patients with hypoplastic left heart syndrome (HLHS) who are poor candidates for single ventricle (SV) palliation, the only recourse is orthotopic heart transplantation, sometimes with strategies to mechanically support the failing SV. ${ }^{1,2}$ Weinstein and colleagues, ${ }^{3}$ using the Berlin EXCOR device (Berlin Heart, Inc, The Woodlands, Tex), noted that patients with SV anatomy had the worst survival before cavopulmonary anastomosis when compared with postbidirectional or total cavopulmonary shunt ( $11 \%$ vs $58 \%$ vs $60 \%$ ). Conway and colleagues, ${ }^{4}$ in an analysis of the Berlin EXCOR experience with the 10-mL pumps, noted that outcomes for patients weighing less than $5 \mathrm{~kg}$ are significantly worse, with $27.3 \%$ survival, and that congenital heart disease was a risk factor for mortality, with $92 \%$ mortality in the subset weighing less than $5 \mathrm{~kg}$ with congenital heart disease. ${ }^{4}$ At our institution, we developed a novel strategy for a neonate with HLHS (weight, $3.75 \mathrm{~kg}$; body surface area, $0.24 \mathrm{~m}^{2}$ ) of combining ventricular support using the Berlin EXCOR device and balance of circulation using hybrid palliation.

\section{CASE REPORT}

In a 39-week-old female patient, weighing $3.75 \mathrm{~kg}$ and prenatally diagnosed with HLHS (mitral/aortic atresia), an echocardiogram demonstrated a severely hypoplastic left ventricle with mitral and aortic atresia, a severely hypoplastic ascending aorta $(0.28 \mathrm{~cm})$, unrestrictive atrial communication, a moderate-sized patent ductus arteriosus, severe tricuspid regurgitation, and deteriorating right ventricular (RV) function. She was deemed a poor candidate for

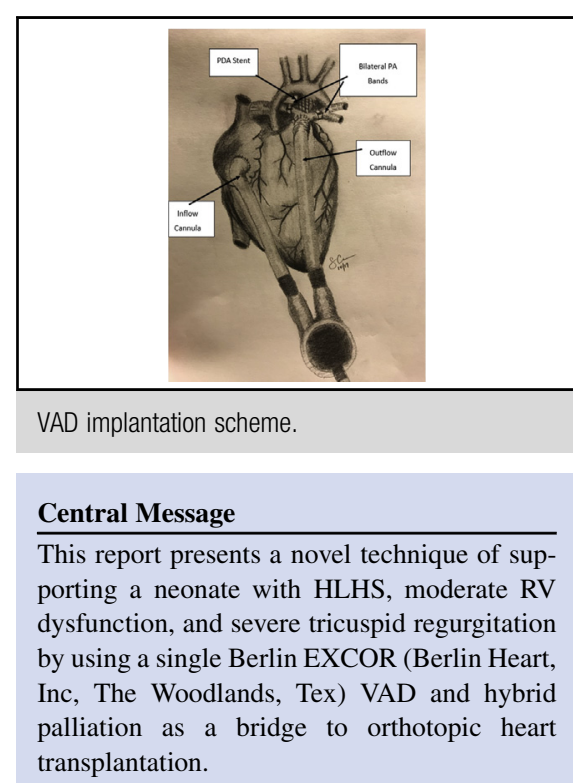

See Commentaries on pages e63 and e65.

palliation and listed for orthotopic heart transplantation. Despite maximal medical therapy, end-organ function continued to worsen and a decision was made to support the patient with combined ventricular assist device (VAD)

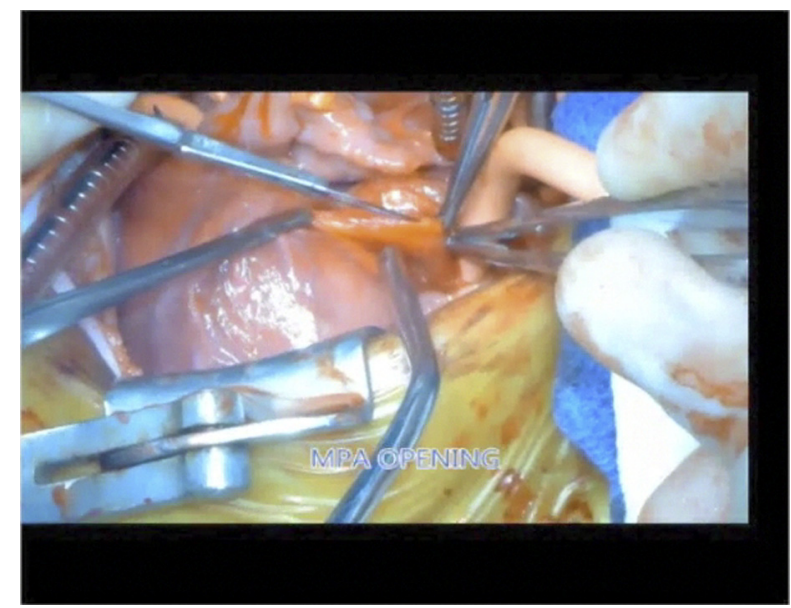

VIDEO 1. Suggested indications and procedure for hybrid procedure with Berlin EXCOR implantation in HLHS. Video available at: https://www. jtcvs.org/article/S0022-5223(18)33464-0/fulltext. 


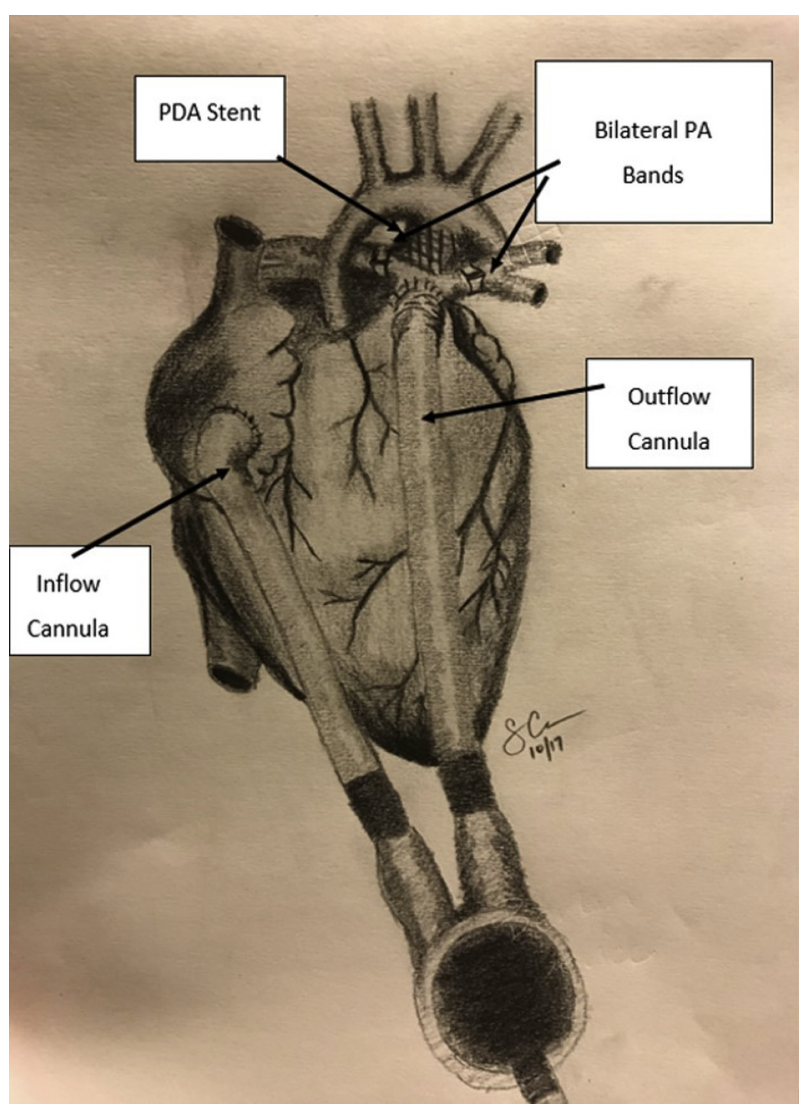

FIGURE 1. Berlin EXCOR (Berlin Heart, Inc, The Woodlands, Tex) implantation schematic in HLHS with hybrid procedure. PDA, Patent ductus arteriosus; $P A$, pulmonary artery.

and stage 1 hybrid palliation to stabilize the systemic circulation and protect the pulmonary vasculature.

A median sternotomy was performed, followed by pericardiotomy and evaluation of the cardiac structures. Cannulation of the innominate artery, superior vena cava, and inferior vena cava was performed in preparation for cardiopulmonary bypass. The right and left pulmonary arteries were banded using a cut ring of a 3.5-mm polytetrafluoroethylene graft. Cardiopulmonary bypass was then established. Subsequently, the right atrium was opened and atrial septectomy was performed. The inflow cannula of the VAD was inserted in the atriotomy incision pursestrings and secured with a Prolene 5-0 continuous suture.
The ductus was then snared with a vessel loop, and the main pulmonary artery was opened. The outflow cannula of the VAD was connected to the main pulmonary artery by attaching the Dacron graft extension at an angle optimal to flow. The cannulas were connected to the VAD after adequate deairing, and the transition was made from cardiopulmonary bypass to the VAD. Heparin was reversed, and the cannulas were removed. Under fluoroscopy, the RV was cannulated with a 6F 11-cm sheath, and a guidewire was passed into the descending aorta. After appropriate measurements, a $10 \times 30$-mm self-expanding stent was deployed in the ductus (Video 1). Postprocedure angiograms confirmed appropriate stent position and pulmonary artery bands. Sternal closure was performed the following day (Figure 1).

The VAD rate was initially set at 70 beats/min with a systolic pressure of $200 \mathrm{~mm} \mathrm{Hg}$, diastolic pressure of $-20 \mathrm{~mm}$ $\mathrm{Hg}$, and cardiac index of $3 \mathrm{~L} / \mathrm{min} / \mathrm{m}^{2}$. Bivalirudin was initiated on postoperative day 1 with a target partial thromboplastin time of 60 to 90 seconds. The VAD rate was gradually increased to provide systemic index (confidence interval, $3.5-4.5 \mathrm{~L} / \mathrm{min} / \mathrm{m}^{2}$ ). The patient was extubated 1 week postprocedure and supported for 40 days with appropriate weight gain and end-organ function before transplantation. Target parameters were not unlike other stage 1 procedures.

\section{DISCUSSION}

Pulsatile VAD and stage 1 hybrid palliation in a neonate has not been previously reported. We have performed this in 5 patients with HLHS (2.5-3.5 kg), with 1 currently awaiting transplant. Patients' 30 -day survival is $100 \%$, with 1 patient currently 1 week from implant. The other patient underwent transplantation after 162 days. Of the other 2 patients, 1 died of severe sepsis (138 days of support) and 1 had support withdrawn ( 56 days of support) because of liver failure from neonatal hemochromatosis (diagnosed postimplant). Reasons for this strategy were severe tricuspid regurgitation and RV dysfunction in 3 patients and RV-dependent coronary fistulization in 2 patients. All patients were anticoagulated with bivalirudin. There were no major VADrelated complications during mechanical support. However, the patient continued to be at risk of cerebral ischemia from the hybrid circulation.

TABLE 1. Combined hybrid procedure Berlin EXCOR (Berlin Heart, Inc, The Woodlands, Tex) ventricular assist device implantation experience

\begin{tabular}{llccccc}
\hline Patient ID & \multicolumn{1}{c}{ Diagnoses } & $\begin{array}{c}\text { Age at } \\
\text { implant (wk) }\end{array}$ & $\begin{array}{c}\text { Weight at } \\
\text { implant }(\mathbf{k g})\end{array}$ & $\begin{array}{c}\text { Days on } \\
\text { support }\end{array}$ & $\begin{array}{c}\text { Cardiac index } \\
\left(\mathbf{L} / \mathbf{m i n} / \mathbf{m}^{2}\right)\end{array}$ & \multicolumn{1}{c}{ Outcomes } \\
\hline 1 & HLHS/severe TR & 3 & 3.95 & 64 & 3.8 & Transplantation \\
2 & HLHS/severe TR & 18 & 3.9 & 138 & 4 & Died \\
3 & HLHS (MS/AA) with coronary fistulae & 2 & 2.4 & 162 & 4.5 & Transplantation \\
\hline 4 & HLHS (MS/AA) with coronary fistulae & 2 & 3.4 & 56 & 4.3 & Support withdrawn \\
\hline 5 & HLHS/severe TR & 3 & 2.9 & Ongoing & Ongoing & Currently on support \\
\hline
\end{tabular}

HLHS, Hypoplastic left heart syndrome; $T R$, tricuspid regurgitation; $M S$, mitral stenosis; $A A$, aortic atresia. 
Other strategies include nonpulsatile/continuous-flow ventricular support. ${ }^{5}$ However, in the largest series to date, risk of bleeding $(29 \%)$, neurologic complications $(24 \%)$, and only a $60 \%$ favorable outcome among patients with SV were noted. ${ }^{6}$ The likely reasons for our success are the anticoagulation strategies and the combination of the hybrid physiology with a targeted higher cardiac index providing a balanced, adequate systemic circulation.

\section{CONCLUSIONS}

Our experience with 5 patients suggests that a pulsatile VAD strategy along with the established hybrid palliation can be a successful long-term option to transplant without significant complications (Table 1). Further studies would help this critical population.

The authors thank Susan Cooke, PA-C, Alan Brock, MD, and Dalia Lopez-Colon, $\mathrm{PhD}$, for their contributions to this article.

\section{References}

1. Pearce FB, Kirklin JK, Holman WL, Barrett CS, Romp RL, Lau YR. Successful cardiac transplant after Berlin Heart bridge in a single ventricle heart: use of aortopulmonary shunt as a supplementary source of pulmonary blood flow. J Thorac Cardiovasc Surg. 2009;137:e40-2.

2. VanderPluym CJ, Rebeyka IM, Ross DB, Buchholz H. The use of ventricular assist devices in pediatric patients with univentricular hearts. J Thorac Cardiovasc Surg. 2011;141:588-90

3. Weinstein S, Bello R, Pizarro C, Flynn-Thompson F, Kirklin J, Guleserian K, et al. The use of the Berlin Heart EXCOR in patients with functional single ventricle. $J$ Thorac Cardiovasc Surg. 2014;147:697-705.

4. Conway J, St Louis J, Morales DL, Law S, Tjossem C, Humpl T. Delineating survival outcomes in children $<10 \mathrm{~kg}$ bridged to transplant or recovery with the Berlin Heart EXCOR ventricular assist device. JACC Heart Fail. 2015;3: 70-7.

5. Mongé MC, Kulat BT, Eltayeb O, Zingle NR, Moss ST, Gossett JG, et al Successful bridge-to-transplant of functionally univentricular patients with a modified continuous-flow ventricular assist device. Artif Organs. 2017;41: 25-31

6. Lorts A, Eghtesady P, Mehegan M, Adachi I, Villa C, Davies R, et al. Outcomes of children supported with devices labeled as "temporary" or short term: a report from the pediatric interagency registry for mechanical circulatory support. J Heart Lung Transplant. 2018;37:54-60. 